\title{
Decreased Reelin Expression in the Left Prefrontal Cortex (BA9) in Chronic Schizophrenia Patients
}

\author{
Gregor Habla, b Andrea Schmitt ${ }^{c, g}$ Mathias Zink ${ }^{a}$ Martina von Wilmsdorff ${ }^{d}$ \\ Peyman Yeganeh-Doost ${ }^{c}$ Alexander Jatzko ${ }^{e}$ Thomas Schneider-Axmann ${ }^{c}$ \\ Manfred Bauer ${ }^{f}$ Peter Falkaic \\ ${ }^{a}$ Central Institute of Mental Health, Mannheim, ${ }^{b}$ Department of Radiation Oncology, University of Heidelberg, \\ Heidelberg, 'Department of Psychiatry, University of Göttingen, Göttingen, ' LVR Klinikum Düsseldorf, Kliniken \\ der Heinrich-Heine-Universität, Düsseldorf, ${ }^{e}$ Department of Psychosomatic Medicine, Westpfalzklinikum- \\ Kaiserslautern, Teaching Hospital, University of Mainz, Mainz, and ${ }^{\mathrm{f}}$ Department of Neuropathology, University of \\ Leipzig, Leipzig, Germany; ${ }^{9}$ Laboratory of Neuroscience (LIM27), Institute of Psychiatry, University of São Paulo, \\ São Paulo, Brazil
}

\section{Key Words}

Reelin · Prefrontal cortex · Gene expression • In situ hybridization $\cdot$ Schizophrenia

\begin{abstract}
Background: Reelin is under epigenetic control and has been reported to be decreased in cortical regions in schizophrenia. Methods: To establish if expression of reelin is altered in specific cortical, hippocampal or thalamic regions of schizophrenia patients, we measured gene expression of reelin in a postmortem study of elderly patients with schizophrenia and non-affected controls in both hemispheres differentiating between gray and white matter. We compared cerebral postmortem samples (dorsolateral prefrontal cortex $B A 9$ and $B A 46$, superior temporal cortex $B A 22$, entorhinal cortex BA28, sensoric cortex BA1-3, hippocampus, CA4, mediodorsal nucleus of the thalamus) from 12 schizophrenia patients with 13 normal subjects investigating gene expression of reelin in the gray and white matter of both hemispheres by in situ-hybridization. Results: The left prefrontal area (BA9) of schizophrenia patients revealed a decreased
\end{abstract}

\section{KARGER}

Fax +4161306 1234

E-Mail karger@karger.ch

www.karger.com
(C) 2012 S. Karger AG, Basel

0302-282X/12/0661-0057\$38.00/0

Accessible online at:

www.karger.com/nps expression of reelin-mRNA of $29.1 \%$ in the white $(p=0.022)$ and $13.6 \%$ in the gray matter $(p=0.007)$ compared to the control group. None of the other regions examined showed any statistically significant differences. Conclusion: Since reelin is responsible for migration and synapse formation, the decreased gene expression of reelin in the left prefrontal area of schizophrenia patients points to neurodevelopmental deficits in neuronal migration and synaptic plasticity. However, our study group was small, and results should be verified using larger samples. Copyright $\odot 2012$ S. Karger AG, Basel

\section{Introduction}

Schizophrenia is a complex neurodevelopmental disorder, where susceptibility genes and environmental factors are assumed to play a role in the pathophysiology of the disease via abnormal connectivity in neuronal net-

G.H. and A.S. contributed equally to the paper.
Prof. Dr. Andrea Schmitt Department of Psychiatry University of Göttingen

Von-Siebold-Str. 5, DE-37075 Göttingen (Germany)

Tel. +49551 391 0366, E-Mail aschmitt@gwdg.de 
Table 1. Characteristics of postmortem samples from patients with schizophrenia and normal comparison subjects

\begin{tabular}{lcc}
\hline Characteristic & $\begin{array}{l}\text { Tissue from } \\
\text { patients with } \\
\text { schizophrenia } \\
(\mathrm{n}=12)\end{array}$ & $\begin{array}{l}\text { Tissue from } \\
\text { normal control } \\
\text { subjects } \\
(\mathrm{n}=13)\end{array}$ \\
\hline Total subjects & 12 & 13 \\
Male & 6 & 11 \\
Female & 6 & 2 \\
Age at death, years & $67.17 \pm 14.06$ & $64.54 \pm 13.58$ \\
Postmortem interval, h & $20.00 \pm 10.49$ & $23.85 \pm 23.12$ \\
pH & $6.42 \pm 0.35$ & $6.65 \pm 0.37$ \\
Age at onset, years & $24.60 \pm 7.36$ & \\
Duration of disease, years & $41.50 \pm 11.70$ & \\
Duration of hospitalization, years & $25.10 \pm 15.32$ & \\
Duration of antipsychotic medication, years & $35.00 \pm 9.72$ & \\
Last dose of antipsychotic medication in CPE, mg & $590.93 \pm 746.62$ & \\
Cumulative dose (last 10 years) of antipsychotic medication CPE, kg & $4.07 \pm 3.09$ & \\
\hline
\end{tabular}

There were no statistically significant differences between age at time of death, PMI and brain pH. Schizophrenia patients were characterized by duration of disease, duration of medication and medication (last dose) in $\mathrm{CPE}$, as well as cumulative dose over the last 10 years in $\mathrm{CPE}$.

Data are presented as $n$ or mean $\pm \mathrm{SD}$.

works [1]. In addition to a number of risk genes, genomewide association studies revealed an association of reelin risk genes with schizophrenia specifically in women [24]. In addition, reelin is under epigenetic controls, and hypermethylation of the reelin promoter has been shown in schizophrenia $[5,6]$.

Reelin is a glycoprotein which controls neuronal migration and synaptic plasticity, suggesting that neurodevelopmental disturbances in schizophrenia are related to its dysfunction [7]. In schizophrenia, reelin expression has been reported to be decreased in prefrontal and temporal cortex, hippocampus, caudate nucleus and cerebellum [8-13], but results in the prefrontal cortex and hippocampus have not been consistent [14]. On the cellular level, interstitial white matter neurons expressed lower levels of reelin in the dorsolateral prefrontal cortex (DLPFC), superior temporal cortex and hippocampus as well as layer I neurons and interneurons of the DLPFC $[15,16]$. Therefore, we hypothesized decreased reelin expression in the DLPFC and investigated its mRNA level in several human brain regions of schizophrenia patients and healthy controls by in situ hybridization, distinguishing between cortical gray and white matter.

\section{Materials and Methods}

\section{Human Postmortem Tissue}

We collected postmortem brain samples from patients with DSM-IV residual schizophrenia $(n=12)$ who had been diagnosed using the DSM-IV checklist of the American Psychiatric Association and elderly comparison subjects $(n=13)$. All schizophrenia patients had been long-term inpatients at the Mental State Hospital Wiesloch, Germany, and had been diagnosed ante-mortem according to DSM-IV criteria [17]. For each patient, the history of antipsychotic treatment was assessed by examining the medical charts. We then calculated the last dose as well as the cumulative dose during the last 10 years of antipsychotic medication in chlorpromazine equivalents (CPE) through the algorithm developed by Jahn and Mussgay [18]. Table 1 outlines the demographic variables. Controls were collected at the Institutes of Neuropathology, Heidelberg University, and University of Bonn, and their clinical records were collected from their relatives and general practitioners. All assessments and postmortem evaluations and procedures had been approved by the Ethics Committee of the Faculty of Medicine of Heidelberg and Bonn Universities, Germany. All patients and controls underwent thorough neuropathologic characterization in order to rule out associated neurovascular or neurodegenerative disorders, such as Alzheimer's disease and multi-infarct dementia [19, 20]. The staging according to Braak was 2 or less for all subjects. Patients and normal comparison subjects had no history of alcohol, drug abuse, or severe physical illness, e.g. carcinoma. Normal comparison subjects had no history of psychiatric disorders.

Postmortem brains were dissected in the midline of the hemispheres. Tissue blocks were prepared from the DLPFC Brodmann 
area (BA) BA9 and BA46, the superior temporal cortex (BA22), the entorhinal cortex (BA28), the sensoric cortex (BA1-3), the hippocampus Cornu Ammonis (CA) CA4 and the mediodorsal nucleus of the thalamus from the right and left hemispheres, respectively. Cortical regions entailed gray and white matter. Blocks were immediately snap-frozen in liquid nitrogen-cooled isopentane and stored at $-80^{\circ} \mathrm{C}$. From these, $10-\mu \mathrm{m}$ sections were cut in triplicate and collected on coated slides. All material was coded, and experiments carried out by researchers blind to diagnosis.

\section{In Situ Hybridization}

In situ hybridization [21] was performed on two sections of each brain region with $\left[{ }^{35} \mathrm{~S}\right]$-UTP-labeled cRNA probes of the reelin gene. Briefly, RNA from human cerebral cortex (RNeasy; Qiagen, Hilden, Germany) was reverse transcribed. After PCR amplification (Promega, Mannheim, Germany) with specific primers derived from reelin (bases 251-710 in Genbank NM 001917), the amplicons were subcloned into gGEM-T vector (Promega, Mannheim, Germany). Correct amplification and orientation were checked by commercial sequencing (MWG, Ebersberg, Germany). Linearized plasmids were transcribed in vitro with Sp6 or T7-RNA polymerase (MBI-Fermentas, St Leon Roth, Germany). Efficiency of incorporation of radioactively labeled [ $\left.{ }^{35} \mathrm{~S}\right]-\mathrm{UTP}$ was measured, and hybridizations with antisense and sense probes using a concentration of $10^{7} \mathrm{cpm} / \mathrm{ml}$ were carried out. After several washing steps including RNAse A digestion, slices were dehydrated and exposed to X-ray films (Biomax MR1 $18 \times 24 \mathrm{~cm}$ ) for 2-6 days.

\section{Image Analysis}

Autoradiographic films were analyzed with a video camera (Sony XC ST 70) and the AIS software (Applied Information Systems, Chapel Hill, N.C., USA). Nonspecific signals were assessed separately for each section in the same regions. These readings were subtracted from gray values in the regions of interest (total binding) resulting in a semiquantitative determination of $\mathrm{mRNA}$ abundance. Gray value images of the coexposed ${ }^{14} \mathrm{C}$ calibration standards (Amersham, UK) were used to compute a calibration curve by nonlinear least squares fitting, which defined the relationship between gray values and concentration of radioactivity.

\section{Statistical Analysis}

Statistical analyses were performed with PASW Statistics 18. All tests were two tailed. The level of significance was $\alpha=0.05$. Distributions for all dependent variables were examined in both groups using histograms and the Kolmogorov-Smirnov test on normality. Due to the small sample size, the power for the Kolmogorov-Smirnov test was not very high. However, the results suggest a normal distribution of the data and analysis by parametric tests.

As initial analyses, in all regions stepwise linear regression analyses with independent variables age, postmortem interval (PMI) and gender were performed, followed by analyses of covariance (ANCOVA) with factor diagnostic group and intervening variables that showed a significant influence in regression analyses. In regions without significant intervening variables, one-way analyses of variance (ANOVA) with factor diagnostic group were calculated. In regions where significant diagnostic group effects were detected, correlations between dependent and intervening variables age, $\mathrm{PMI}$, brain $\mathrm{pH}$ and disease duration were per- formed using Pearson correlation coefficients. As there were extreme values for medication doses in CPE, we calculated Spearman rank correlation for medication variables. Correlations were computed separately for schizophrenia patients and - if present - for controls.

This is an explorative study aimed at finding variables that may show differences in the expression of reelin-mRNA between schizophrenia patients and control subjects. If a Bonferroni adjustment of the error probability of first kind for the number of statistical tests was applied, no significant differences between schizophrenia patients and controls would remain. However, an adjustment of the error probability would decrease the test power to such an extent that the power of detecting existing mean differences would be very low. Thus, the present results are presented without error probability correction. Due to the explorative study design and the problems of multiple testing, these findings offer no conclusive evidence for a causal relationship. An independent larger sample has to be analyzed in an effort to confirm the positive findings of this study.

\section{Results}

Schizophrenia patients did not differ from controls in terms of age $(\mathrm{F}=0.3$, d.f. $=1,23 ; \mathrm{p}=0.62), \mathrm{pH}(\mathrm{F}=0.5$, d.f. $=1,20 ; \mathrm{p}=0.68)$, PMI $(\mathrm{F}=0.2$, d.f. $=1,23 ; \mathrm{p}=0.69)$ or gender $\left(\chi^{2}=3.44\right.$, d.f. $\left.=1 ; \mathrm{p}=0.064\right)$ compared to controls. Stepwise linear regression analyses showed a significant influence of PMI on the gray matter of BA9, left side $(\mathrm{p}=0.019)$, and BA46 [gray matter, left side $(\mathrm{p}=$ $0.032)$, white matter, right side $(\mathrm{p}=0.022)$, gray matter, right side $(\mathrm{p}=0.005)]$, and on age in BA46, gray matter, left side $(\mathrm{p}=0.021)$ and in the sensomotoric cortex BA13 , gray matter, left side $(\mathrm{p}=0.024)$. Descriptives for specific bindings in the analyzed regions are shown in table 2. Using ANOVA, we detected a decreased expression of $29.1 \%(F=7.6$; d.f. $=1,9 ; p=0.022)$ on the white matter of the left BA9 of schizophrenia patients compared to the control group. From ANCOVA (factor diagnosis, covariate $\mathrm{PMI}$ ) intending to adjust the analysis on diagnostic effects for this intervening variable, the decreased reelinmRNA expression in schizophrenic patients was significant in the gray matter $(-13.6 \%)$ of the left prefrontal cortex, BA9 ( $F=9.6$, d.f. $=1,15 ; \mathrm{p}=0.007$; fig. 1$)$. In all other gray and white matter regions [the middle frontal cortex (BA46), the superior temporal cortex (BA22), the entorhinal cortex (BA28), hippocampal CA4, the sensoric cortex (BA1-3), and the mediodorsal nucleus of the thalamus], we did not find statistically significant diagnostic group differences in the expression of reelin (table 2).

The number of female subjects in the control sample was very small. However, for all regions, we have per- 
Fig. 1. Scatter plots of significant results (expression of reelin) in the gray and white matter of BA9.



Table 2. Descriptive statistics for specific bindings in the analyzed brain regions in schizophrenic patients and controls

\begin{tabular}{|c|c|c|c|c|}
\hline Region & \multicolumn{2}{|c|}{ Left hemisphere } & \multicolumn{2}{|c|}{ Right hemisphere } \\
\hline BA9 prefrontal cortex (gray matter) & $1,427 \pm 321$ & $1,232 \pm 191^{* *}$ & $1,290 \pm 362$ & $1,398 \pm 140$ \\
\hline BA46 middle frontal cortex (white matter) & $2,500 \pm 1,216$ & $2,241 \pm 585$ & $2,408 \pm 985$ & $2,494 \pm 759$ \\
\hline BA46 middle frontal cortex (gray matter) & $1,406 \pm 630$ & $1,489 \pm 347$ & $1,449 \pm 468$ & $1,492 \pm 417$ \\
\hline BA1-3 sensoric cortex (white matter) & $1,904 \pm 226$ & $2,382 \pm 1,525$ & $1,770 \pm 316$ & $2,138 \pm 671$ \\
\hline BA1-3 sensoric cortex (gray matter) & $1,371 \pm 243$ & $1,620 \pm 467$ & $1,329 \pm 336$ & $1,517 \pm 331$ \\
\hline Hippocampus (CA4) & $1,680 \pm 376$ & $1,832 \pm 500$ & $1,404 \pm 233$ & $1,749 \pm 313$ \\
\hline BA28 entorhinal cortex (white matter) & $1,889 \pm 426$ & $1,860 \pm 583$ & $1,886 \pm 551$ & $2,118 \pm 645$ \\
\hline BA28 entorhinal cortex (gray matter) & $1,213 \pm 244$ & $1,169 \pm 328$ & $1,149 \pm 262$ & $1,355 \pm 442$ \\
\hline Mediodorsal nucleus of the thalamus & $2,115 \pm 510$ & $1,985 \pm 829$ & $1,975 \pm 352$ & $1,944 \pm 643$ \\
\hline
\end{tabular}

Data are given in $\mathrm{Bq} / \mathrm{mg}$ brain tissue and are presented as mean $\pm \mathrm{SD}$. There was a significant difference in the left white matter $(\mathrm{p}=0.022)$ and gray matter of BA9 $(\mathrm{p}=0.007)$ between schizophrenia patients and controls. ${ }^{*} \mathrm{p}=0.022,{ }^{* *} \mathrm{p}=0.007$.

formed linear stepwise regression analyses with independent variables gender, age and PMI, and there was not any significant predictive gender influence. In line with this result, there were no significant gender effects in all regions when comparing the data of all male and female subjects with one-way ANOVA. When performing group comparisons adjusted for gender [ANOVA (group $\times$ gender) or ANCOVA (group $\times$ gender, covariate PMI)], respectively, we still revealed a significantly decreased expression in the white matter of the left BA9 in schizophrenia patients of both genders (male: schizophrenia vs. controls: $-14.1 \%$, female: schizophrenia vs. controls: $-58.9 \%$, 
factor diagnosis: $\mathrm{F}=40.8$, d.f. $=1,7 ; \mathrm{p}<0.0005)$ as well as a decreased expression in the gray matter of the left BA9 in schizophrenia patients of both genders (male: schizophrenia vs. controls: $-12.4 \%$, female: schizophrenia vs. controls: $-9.9 \%$, factor diagnosis: $F=9.0$, d.f. $=1$, $13 ; \mathrm{p}=0.010$ ).

In controls, but not in schizophrenia patients, there was a significant negative correlation between PMI and reelin expression ( $\mathrm{r}=-0.93$, d.f. $=5 ; \mathrm{p}=0.003)$ in the left gray matter of BA9. In this region in patients, the last dose of antipsychotics in CPE showed a significant influence on specific binding of reelin ( $r h o=0.66$, d.f. $=9 ; \mathrm{p}=$ $0.026)$.

\section{Discussion}

In this study in schizophrenia patients, we detected decreased expression exclusively in the gray and white matter of the DLPFC (BA9), but not in other cortical or subcortical brain regions. Thus, we extended previous results showing decreased reelin expression in the frontal cortex in schizophrenia $[8,11-13]$, but we could not confirm decreased expression in temporal cortex and hippocampus [8]. However, in these regions we investigated specific regions (BA22, CA4), and in other BAs decreased expression may be detected. In addition, we used in situ hybridization in specific gray and white matter subregions, allowing more detailed analysis than RT-PCR in tissue blocks composed of different gray and white matter compartments. However, to verify quantitative measurements, results should be confirmed by real-time PCR and Western blotting on the protein level.

The PMI may influence mRNA integrity, and in our study, using regression and correlation analysis, we detected an influence of PMI on reelin expression in the gray matter of BA9. However, the correlation was significantly negative in controls, not in schizophrenia patients, and ANCOVA with PMI as intervening variable showed significant differences in gray matter. Since all patients had been treated with antipsychotics until death, medication may have influenced our results. However, we detected a positive correlation between last dosage in $\mathrm{CPE}$ and reelin expression in the gray matter of BA9, allowing the assumption that decreased reelin levels may not be related to higher antipsychotic doses and thus excluding effects of dosage in CPE on reelin expression. Some of our patients had been treated with clozapine, which has been shown to activate DNA demethylation of the reelin promoter in the frontal cortex of mice, suggesting an influ- ence on gene expression [22]. However, the frontal cortex of mice belongs to the motor cortex and is not comparable to human prefrontal cortex. Additionally, these mice were pretreated with L-methionine to hypermethylate promoters. Effects of antipsychotics should be assessed in validated animal models for risk factors of schizophrenia.

A further limitation is the small number of females in the control sample (only 2). Since genetic evidence suggests reelin-associated effects only in females [2-4], this bias could make a difference. However, in our statistical analysis, we did not detect effects of gender, and epigenetic mechanisms may also decrease reelin expression in male patients $[5,6]$. Hence, our results should be confirmed in a larger sample including more females.

Our results confirm previous studies showing increased epigenetic promoter hypermethylation in the prefrontal cortex of schizophrenia patients, which may lead to decreased gene expression $[5,6]$. Moreover, reelin expression was associated with decreased expression of synaptic proteins, supporting the role of reelin in disturbed synaptic plasticity in schizophrenia $[15,16]$. In animal studies, a deficit in the reelin gene is associated with a failure of neuroblasts to penetrate the subplate, resulting in disturbances of neuronal migration [23]. In schizophrenia, abnormal positioning of neurons during neuronal migration has been shown and related to neurodevelopmental disturbances in the pathophysiology of the disease $[24,25]$. Apart from the fact that involvement of a mutation of the reelin gene has not consistently been reported in schizophrenia [7], an association of a reelin risk allele with working memory dysfunction and more severe positive and negative symptoms has been shown in large cohorts of schizophrenia patients [26,27]. Therefore, reelin may be considered as a modifier gene in an interplay with genetic and environmental, epigenetic factors in schizophrenia. Further postmortem studies should relate genetic and epigenetic factors to reelin expression in the DLPFC.

\section{Acknowledgements}

This study was supported by the European Commission under the Sixth Framework Programme (BrainNet Europe II, LSHMCT-2004-503039). The paper reflects only the authors' views, and the Community is not liable for any use that may be made of it. The authors would like to thank Udo Rueb for Braak staging. 


\section{References}

$\checkmark 1$ Weinberger DR: On the plausibility of 'the neurodevelopmental hypothesis' of schizophrenia. Neuropsychopharmacology 1996; 14:1-11.

2 Shifman S, Johannesson M, Bronstein M, Chen SX, Collier DA, Craddock NJ, Kendler KS, Li T, O’Donovan M, O’Neill FA, Owen MJ, Walsh D, Weinberger DR, Sun C, Flint J, Darvasi A: Genome-wide association identifies a common variant in the reelin gene that increases the risk of schizophrenia only in women. PLoS Genet 2008;4:e28.

-3 Ben-David E, Shifman S, International Schizophrenia Consortium: Further investigation of the association between rs7341475 and rs17746501 and schizophrenia. Am J Med Genet B Neuropsychiatr Genet 2010; 153B:1244-1247.

4 Liu Y, Chen PL, McGrath J, Wolyniec P, Fallin D, Nestadt G, Liang KY, Pulver A, Valle D, Avramopoulos D: Replication of an association of a common variant in the Reelin gene (RELN) with schizophrenia in Ashkenazi Jewish women. Psychiatr Genet 2010; 20:184-186.

5 Grayson DR, Jia X, Chen Y, Sharma RP, Mitchell CP, Guidotti A, Costa E: Reelin promoter hypermethylation in schizophrenia. Proc Natl Acad Sci USA 2005;102:93419346.

6 Abdolmaleky HM, Cheng KH, Russo A, Smith CL, Faraone SV, Wilcox M, Shafa R, Glatt SJ, Nguyen G, Ponte JF, Thiagalingam S, Tsuang MT: Hypermethylation of the reelin (RELN) promoter in the brain of schizophrenic patients: a preliminary report. Am J Med Genet B Neuropsychiatr Genet 2005; 134B:60-66.

7 Knuesel I: Reelin-mediated signaling in neuropsychiatric and neurodegenerative diseases. Prog Neurobiol 2010;91:257-274.

8 Impagnatiello F, Guidotti AR, Pesold C, Dwivedi Y, Caruncho H, Pisu MG, Uzunov DP, Smalheiser NR, Davis JM, Pandey GN, Pappas GD, Tueting P, Sharma RP, Costa E: A decrease of reelin expression as a putative vulnerability factor in schizophrenia. Proc Natl Acad Sci USA 1998;95:15718-15723. $\checkmark 9$ Fatemi SH, Earle JA, McMenomy T: Reduction in reelin immunoreactivity in hippocampus of subjects with schizophrenia, bipolar disorder and major depression. Mol Psychiatry 2000;5:654-563, 571.

10 Fatemi SH, Kroll JL, Stary JM: Altered levels of reelin and its isoforms in schizophrenia and mood disorders. Neuroreport 2001;12: 3209-3215.

11 Guidotti A, Auta J, Davis JM, Di-Giorgi-Gerevini V, Dwivedi Y, Grayson DR, Impagnatiello F, Pandey G, Pesold C, Sharma R, Uzunov D, Costa E: Decrease in reelin and glutamic acid decarboxylase 67 (GAD67) expression in schizophrenia and bipolar disorder: a postmortem brain study. Arch Gen Psychiatry 2000;57:1061-1069, erratum in Arch Gen Psychiatry 2002;59:12.

12 Torrey EF, Barci BM, Webster MJ, Bartko JJ, Meador-Woodruff JH, Knable MB: Neurochemical markers for schizophrenia, bipolar disorder, and major depression in postmor tem brains. Biol Psychiatry 2005 1;57:252260.

13 Kim S, Webster MJ: The Stanley neuropathology consortium integrative database: a novel, web-based tool for exploring neuropathological markers in psychiatric disorders and the biological processes associated with abnormalities of those markers. Neuropsychopharmacology 2010;35:473-482.

14 Lipska BK, Mitkus SN, Mathew SV, Fatula R, Hyde TM, Weinberger DR, Kleinman JE: Functional genomics in postmortem human brain: abnormalities in a DISC1 molecular pathway in schizophrenia. Dialogues Clin Neurosci 2006;8:353-357.

15 Eastwood SL, Harrison PJ: Interstitial white matter neurons express less reelin and are abnormally distributed in schizophrenia: towards an integration of molecular and morphologic aspects of the neurodevelopmental hypothesis. Mol Psychiatry 2003;8:769, 821831.

16 Eastwood SL, Harrison PJ: Cellular basis of reduced cortical reelin expression in schizophrenia. Am J Psychiatry 2006;163:540-542.

17 American PA: Diagnostic and Statistical Manual of Mental Disorders, ed 4. Washington, American Psychiatric Association, 1994.

18 Jahn T, Mussgay L: Die statistische Kontrolle möglicher Medikamenteneinflüsse in experimentalpsychologischen Schizophreniestudien: ein Vorschlag zur Berechnung von Chlorpromazinäquivalenten. Z Klin Psychol 1989;18:257-267.
19 Braak H, Braak E: Neuropathological stageing of Alzheimer-related changes. Acta Neuropathol 1991;82:239-259.

20 Braak H, Alafuzoff I, Arzberger T, Kretzschmar H, Del Tredici K: Staging of Alzheimer disease-associated neurofibrillary pathology using paraffin sections and immunocytochemistry. Acta Neuropathol 2006;112:389-404

21 Habl G, Zink M, Petroianu G, Bauer M, Schneider-Axmann T, von Wilmsdorff M, Falkai P, Henn FA, Schmitt A: Increased Damino acid oxidase expression in the bilateral hippocampal CA4 of schizophrenic patients: a post-mortem study. J Neural Transm 2009;116:1657-1665.

22 Dong E, Nelson M, Grayson DR, Costa E, Guidotti A: Clozapine and sulpiride but not haloperidol or olanzapine activate brain DNA demethylation. Proc Natl Acad Sci USA 2008;105:13614-13619.

23 Costa E, Davis J, Grayson DR, Guidotti A, Pappas GD, Pesold C: Dendritic spine hypoplasticity and downregulation of reelin and GABAergic tone in schizophrenia vulnerability. Neurobiol Dis 2001;8:723-742.

24 Jakob H, Beckmann H: Prenatal developmental disturbances in the limbic allocortex in schizophrenics. J Neural Transm 1986;65: 303-326.

-25 Falkai P, Schneider-Axmann T, Honer WG: Entorhinal cortex pre-alpha cell clusters in schizophrenia: quantitative evidence of a developmental abnormality. Biol Psychiatry 2000;47:937-943.

26 Wedenoja J, Loukola A, Tuulio-Henriksson A, Paunio T, Ekelund J, Silander K, Varilo T, Heikkilä K, Suvisaari J, Partonen T, Lönnqvist J, Peltonen L: Replication of linkage on chromosome 7q22 and association of the regional Reelin gene with working memory in schizophrenia families. Mol Psychiatry 2008;13:673-684.

27 Wedenoja J, Tuulio-Henriksson A, Suvisaari J, Loukola A, Paunio T, Partonen T, Varilo T, Lönnqvist J, Peltonen L: Replication of association between working memory and Reelin, a potential modifier gene in schizophrenia. Biol Psychiatry 2010;67:983-991. 